\title{
. \\ Combined Treatment with Immunotherapy-Based Strategies for MSS Metastatic Colorectal Cancer
}

\author{
Iosune Baraibar ${ }^{1,2, * \mathbb{D}}$, Oriol Mirallas ${ }^{1} \mathbb{D}$, Nadia Saoudi ${ }^{1,2}$, Javier Ros ${ }^{1,2} \mathbb{D}$, Francesc Salvà ${ }^{1,2}$, Josep Tabernero ${ }^{1,2}$ \\ and Elena Élez ${ }^{1,2}$
}

1 Department of Medical Oncology, Vall d'Hebron University Hospital, Passeig de la Vall d'Hebron, 119, 08035 Barcelona, Spain; omirallas@vhebron.net (O.M.); nsaoudi@vhio.net (N.S.); fjros@vhio.net (J.R.); fsalva@vhio.net (F.S.); jtabernero@vhio.net (J.T.); meelez@vhio.net (E.É.)

2 Vall d'Hebron Institute of Oncology (VHIO), 08035 Barcelona, Spain

* Correspondence: ibaraibar@vhio.net

Citation: Baraibar, I.; Mirallas, O.; Saoudi, N.; Ros, J.; Salvà, F.; Tabernero, J.; Élez, E. Combined Treatment with Immunotherapy-Based Strategies for MSS Metastatic Colorectal Cancer. Cancers 2021, 13, 6311. https:// doi.org/10.3390/cancers13246311

Academic Editor: Sandra J. van Vliet

Received: 8 November 2021

Accepted: 14 December 2021

Published: 16 December 2021

Publisher's Note: MDPI stays neutral with regard to jurisdictional claims in published maps and institutional affiliations.

Copyright: (c) 2021 by the authors. Licensee MDPI, Basel, Switzerland. This article is an open access article distributed under the terms and conditions of the Creative Commons Attribution (CC BY) license (https:/ / creativecommons.org/licenses/by/ $4.0 /)$.
Simple Summary: Given that most patients with MSS mCRC do not respond to immunotherapy agents or do not have durable clinical responses, there is an unmet clinical need to obtain predictors of response to immunotherapy and rational immunotherapy-based combination therapies for this entity. In this review, we present the efforts that have been made to date in the clinical setting to develop immunotherapy-based combinations for MSS $\mathrm{mCRC}$ and the rationale that lies behind each strategy.

Abstract: In recent years, deepening knowledge of the complex interactions between the immune system and cancer cells has led to the advent of effective immunotherapies that have revolutionized the therapeutic paradigm of several cancer types. However, colorectal cancer (CRC) is one of the tumor types in which immunotherapy has proven less effective. While there is solid clinical evidence for the therapeutic role of immune checkpoint inhibitors in mismatch repair-deficient (dMMR) and in highly microsatellite instable (MSI-H) metastatic CRC (mCRC), blockade of CTLA-4 or PD-L1/PD-1 as monotherapy has not conferred any major clinical benefit to patients with MMR-proficient (pMMR) or microsatellite stable (MSS) $\mathrm{mCRC}$, reflecting $95 \%$ of the CRC population. There thus remains a high unmet medical need for the development of novel immunotherapy approaches for the vast majority of patients with pMMR or MSS/MSI-low (MSI-L) mCRC. Defining the molecular mechanisms for immunogenicity in $\mathrm{mCRC}$ and mediating immune resistance in MSS mCRC is needed to develop predictive biomarkers and effective therapeutic combination strategies. Here we review available clinical data from combinatorial therapeutic approaches using immunotherapy-based strategies for MSS mCRC.

Keywords: colorectal cancer; microsatellite stable; mismatch repair-proficiency; immunotherapy; immune checkpoint inhibitors; cold tumor; combined treatment

\section{Introduction}

Colorectal cancer (CRC) is the third most common primary tumor worldwide and ranks second in terms of mortality [1]. CRC is a heterogeneous disease that remains a largely unsolved clinical challenge. This heterogeneity characterizes CRC at several levelsincluding genomic, epigenomic, transcriptomic, and microenvironmental features [2]. Current management of metastatic CRC (mCRC) is based on the tumor molecular profile and the individual patient's clinical condition. Validated biomarker-drug matches that guide treatment decisions in the metastatic setting are available, including $R A S / B R A F$ mutations conferring resistance to anti-EGFR agents and $B R A F-\mathrm{V} 600 \mathrm{E}$ mutations sensitizing tumors to anti-BRAF therapies. There is growing evidence for other biomarkers, including HER2 amplifications. 
Microsatellite instability (MSI) status is currently the main biomarker for immunotherapeutic response in mCRC. The advent of immunotherapy-including programmed cell death 1 (PD-1), programmed cell death-ligand 1 (PD-L1), and cytotoxic T-lymphocyte antigen 4 (CTLA-4) immune checkpoint inhibitors-has revolutionized the therapeutic paradigm across a wide range of cancers. It has increased treatment options, leading to remarkable improvements in terms of response rate, survival, and quality of life in many different tumor types, and has been positioned as frontline therapy, second-line therapy, and beyond in many solid tumors. The underlying mechanism of action relies on the upregulation of the immune system to reverse the immunosuppression provoked by cancer cells to evade an antitumor $\mathrm{T}$ cell response. In CRC, the beneficial effect of immune checkpoint inhibitors observed in patients with mCRC harboring deficient mismatch repair (dMMR) and MSI has been ascribed to the abundance of DNA replication errors due to the loss of function of any of the DNA mismatch machinery proteins, including MSH2, MSH6, MLH1, and PMS2 [3], that leads to a hypermutated phenotype. These tumors are characterized by high tumor mutational burden (TMB) and by consequence an inflammatory tumor microenvironment (TME), comprising infiltrating lymphocytes (TILs), and notably memory cells and cytotoxic T lymphocytes (CTLs) [4].

Otherwise, CRC is considered to be a cold tumor with a low number of neoantigens and an immune-excluded or immune-desert TME with absent or inactive TILs [5]. Therefore, while immune checkpoint inhibitors-such as anti-PD-1, anti-PD-L1, and anti-CTLA-4 agents-have demonstrated efficacy as frontline therapy as reported in the KEYNOTE-177 study in patients with previously-treated dMMR CRC who have progressed on fluoropyrimidines, oxaliplatin, and irinotecan [6], they fail to provide benefit to $95 \%$ of patients with mCRC defined as proficient mismatch repair (pMMR) or microsatellite stable (MSS) tumors.

Five single-arm trials (phase Ib KEYNOTE 012 and 028, and phase II KEYNOTE 016, 164, and 158) investigated the anti-PD-1 agent pembrolizumab across different tumor types, including 149 patients with previously-treated advanced CRC, 59 of whom presented MSS/pMMR tumors. Forty-one patients with metastatic MSI-H or MSS carcinoma included in the phase II KEYNOTE-016 clinical trial received treatment with pembrolizumab [7].

The overall response rate (ORR) in patients with dMMR was $71 \%$ (5 of 7 patients) and $40 \%$ (4 of 10 patients) for non-CRC and CRC, respectively, while the ORR in patients with pMMR was $0 \%$ ( 0 of 18 patients). The immune-related progression-free survival (PFS) rate at 20 weeks was $67 \%$ (4 of 6 patients), $78 \%$ (7 of 9 patients), and $11 \%$ (2 of 18 patients), for dMMR non-CRC, dMMR CRC, and pMMR CRC, respectively. These data support the hypothesis that, regardless of the primary tumor origin, the large proportion of mutant neoantigens in dMMR tumors make them sensitive to immune checkpoint inhibitors. [8]. However, it should be noted that, similarly to dMMR/MSI tumors, response to pembrolizumab has been reported in a patient with MSS mCRC harboring POLE mutations (which encodes the DNA polymerase $\varepsilon$ responsible for lead strand DNA replication) [9]. This antitumor activity might be mediated by an increase in the expression of cytotoxic T-cell markers and effector cytokines and a higher intratumoral $\mathrm{CD} 8^{+}$lymphocyte infiltration [10].

Thus, given that most patients with MSS mCRC do not respond to immunotherapy or do not have durable clinical responses, it is necessary to obtain predictors of response to immunotherapy and rational immunotherapy-based combination therapies. The cornerstone of developing biologically sound combination therapies for MSS CRC is to unravel the mechanisms underlying primary or acquired resistance to immunotherapy and enhance efficacy. Novel strategies involve prompting the immune cycle at various levels, either by heightening the TMB and the number of neoantigens, by impacting the interferon- $\gamma$ (IFN- $\gamma$ ) signature with inhibition of immunosuppressive ligands expression, or by transforming the TME into an immune response phenotype with effective immune cells.

In this review, we present the efforts to date to develop immunotherapy-based combinations for MSS $\mathrm{mCRC}$ in the clinical setting. A retrospective review of the literature was conducted by searching PubMed, MEDLINE, Cochrane, and ClinicalTrials.gov databases, 
using the following MeSH terms: "colorectal cancer", "immunotherapy", and "pMMR" or "proficient mismatch repair".

\section{Immunotherapy-Based Combinations in pMMR/MSS mCCR}

Novel immunotherapy-based approaches have been developed under the rationale of overcoming immune resistance and developing an effective immune response against tumor cells, such as combined strategies of immune checkpoint inhibition, immunotherapybased combinations with chemotherapy and targeted therapy, radiation therapy, vaccines, and intratumoral strategies such as oncolytic viruses and bispecific antibodies (Figure 1, Table 1).
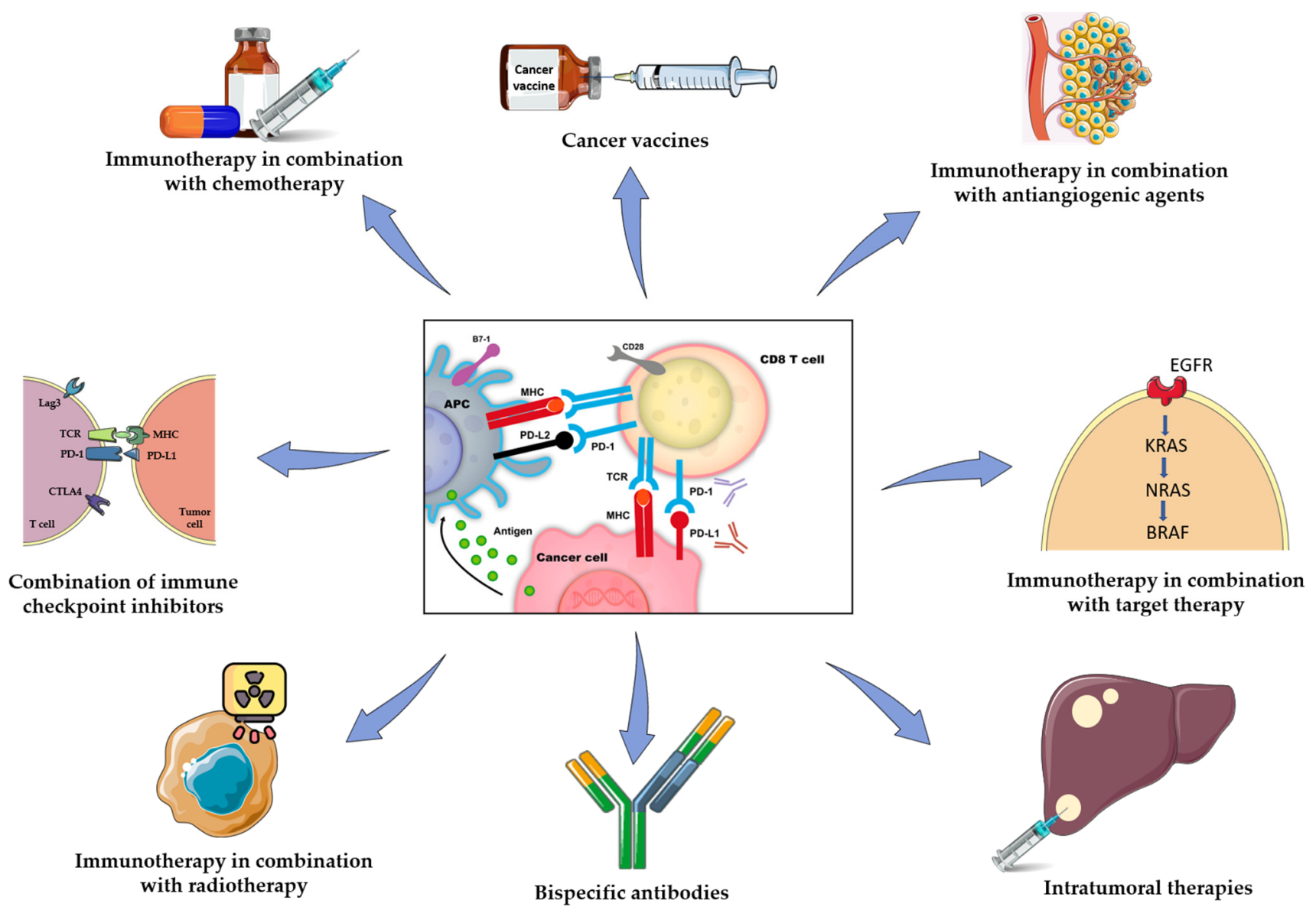

Figure 1. Approaches investigated so far to overcome immune resistance and develop an effective immune response against tumor cells for MSS mCRC. Created with smart.servier.com, accessed on 8 December 2021.

Inhibition of the PD-1/PDL-1 axis alone has proven insufficient for $\mathrm{pMMR} / \mathrm{MSS}$ mCRC. Novel and a range of immunotherapy-based approaches have been developed based on the rationale of overcoming immune resistance and developing an effective immune response against tumor cells. 
Table 1. Summary of clinical trials investigating the use of immunotherapy-based combinations for MSS mCCR.

\begin{tabular}{|c|c|c|c|c|c|c|c|}
\hline Study & Treatment & Phase & Setting & Sample Size & ORR & Median PFS & Median OS \\
\hline \multicolumn{8}{|c|}{ Combination of immune checkpoint inhibitors } \\
\hline CCTG CO.26 [11] & Durvalumab + Tremelimumab vs. BSC & II & Refractory & 119 vs. 61 & $0.5 \%$ vs. $0 \%$ & 1.8 vs. 1.9 months & 6.6 vs. 4.1 months \\
\hline NCT02720068 [12] & Pembrolizumab + Favezelimab & I & Refractory & 80 & $6.3 \%$ & 2.1 months & 8.3 months \\
\hline \multicolumn{8}{|c|}{ Immunotherapy in combination with chemotherapy } \\
\hline \multicolumn{8}{|c|}{ Immunotherapy in combination with chemotherapy and anti-VEGF agents } \\
\hline MODUL [13] & $\begin{array}{l}\text { FOLFOX }+ \text { Bevacizumab followed by } 5-\mathrm{FU}+ \\
\text { Bevacizumab }+ \text { Atezolizumab vs. 5-FU }+ \\
\text { Bevacizumab }\end{array}$ & II & First line & 297 vs. 148 & NA & 7.2 vs. 7.39 months & 22 vs. 21.9 months \\
\hline ATEZOTRIBE [14] & $\begin{array}{l}\text { FOLFOX + Bevacizumab + Atezolizumab vs. } \\
\text { FOLFOX + Atezolizumab }\end{array}$ & III & First line & 132 vs. 67 & $59 \%$ vs. $64 \%$ & 12.9 vs. 11.4 months & NA \\
\hline CA2099 $\times 8$ & $\begin{array}{l}\text { FOLFOX + Bevacizumab + Nivolumab vs. } \\
\text { FOLFOX + Bevacizumab }\end{array}$ & $\mathrm{II} / \mathrm{III}$ & First line & Active & NA & NA & NA \\
\hline COLUMBIA-1 & $\begin{array}{l}\text { FOLFOX + Bevacizumab + Durvalumab + } \\
\text { Oleclumab vs. FOLFOX + Bevacizumab }\end{array}$ & II & First line & Active & NA & NA & NA \\
\hline NIVACOR (NCT04072198) & FOLFOXIRI + Bevacizumab + Nivolumab & II & First line & Recruiting & NA & NA & NA \\
\hline BACCI (NCT0287319) [15] & $\begin{array}{l}\text { Capecitabine + Bevacizumab + Atezolizumab vs. } \\
\text { Capecitabine + Bevacizumab }\end{array}$ & II & Refractory & 82 vs. 46 & $8.5 \%$ vs. $4.3 \%$ & 4.4 vs. 3.3 months & NA \\
\hline \multicolumn{8}{|c|}{ Immunotherapy in combination with chemotherapy and anti-EGFR agents } \\
\hline AVETRIC (NCT04513951) & FOLFOXIRI + Cetuximab + Avelumab & II & First line & Recruiting & NA & NA & NA \\
\hline AVETUX (NCT03174405) [16] & FOLFOX + Cetuximab + Avelumab & II & First line & 43 & $79.5 \%$ & 11.5 months & NA \\
\hline \multicolumn{8}{|c|}{ Immunotherapy in combination with temozolomide } \\
\hline MAYA [17] & Temozolomide + Nivolumab + Ipilimumab & II & Refractory & 33 & $42 \%$ & 7.1 months & 18.4 months \\
\hline \multicolumn{8}{|c|}{ Immunotherapy in combination with antiangiogenic agents } \\
\hline LEAP-005 [18] & Pembrolizumab + Lenvatinib & II & Refractory & 32 & $22 \%$ & 2.3 months & 7.5 months \\
\hline REGONIVO [19] & Nivolumab + Regorafenib & $\mathrm{Ib}$ & Refractory & 25 & $36 \%$ & 7.9 months & NA \\
\hline REGOMUNE [20] & Avelumab + Regorafenib & II & $\geq 2$ lines & 48 & $0 \%$ & 3.6 months & 10.8 months \\
\hline \multicolumn{8}{|c|}{ Immunotherapy in combination with radiotherapy } \\
\hline NCT03122509 [21] & Radiotherapy + Durvalumab + Tremelimumab & II & $>2$ lines & 24 & $8.3 \%$ & 1.8 months & 11.4 months \\
\hline NCT03104439 [22] & SBRT + Nivolumab + Ipilimumab & II & $>2$ lines & 40 & $12,5 \%$ & NA & NA \\
\hline NCT02992912 & SABR + Atezolizumab & II & Refractory & Recruiting & NA & NA & NA \\
\hline
\end{tabular}


Table 1. Cont.

\begin{tabular}{|c|c|c|c|c|c|c|c|}
\hline Study & Treatment & Phase & Setting & Sample Size & ORR & Median PFS & Median OS \\
\hline \multicolumn{8}{|c|}{$\begin{array}{l}\text { Immunotherapy in combination with MAPK signaling inhibitors } \\
\text { Immunotherapy in combination with KRAS inhibitors }\end{array}$} \\
\hline CodeBreaK 100 & AMG $510+/-$ AntiPD-1/L1 & I/II & Refractory & Recruiting & NA & NA & NA \\
\hline NCT04699188 & $\mathrm{JDQ} 443+/-\mathrm{TNO} 155+/$ - Spartalizumab & $\mathrm{I} / \mathrm{II}$ & Refractory & Recruiting & NA & NA & NA \\
\hline \multicolumn{8}{|c|}{ Immunotherapy in combination with BRAF inhibitors } \\
\hline NCT03668431 & Dabrafenib + Trametinib (MEK) + Spartalizumab & II & Refractory & Recruiting & NA & NA & NA \\
\hline NCT04294160 & Dabrafenib + LTT462 (ERK) + Spartalizumab & I & Refractory & Recruiting & NA & NA & NA \\
\hline \multicolumn{8}{|c|}{ Immunotherapy in combination with MEK inhibitors } \\
\hline NCT01988896 [23] & Cobimetinib + Atezolizumab & $\mathrm{I} / \mathrm{Ib}$ & Refractory & 84 & $8 \%$ & 1.9 months & 9.8 months \\
\hline IMBlaze 370 [24] & $\begin{array}{l}\text { Atezolizumab + Cobimetinib vs. Atezolizumab vs. } \\
\text { Regorafenib }\end{array}$ & III & Refractory & 183 vs. 90 vs. 90 & $3 \%$ & 1.9 vs. 1.9 vs. 2 months & 8.9 vs. 7.1 vs. 8.5 months \\
\hline \multicolumn{8}{|c|}{ Immunotherapy in combination with inhibition of the PI3K/AKT/mTOR pathway } \\
\hline NCT03711058 [25] & Copanlisib + Nivolumab & $\mathrm{I} / \mathrm{II}$ & Refractory & Recruiting & NA & NA & NA \\
\hline \multicolumn{8}{|l|}{ Biespecific antibodies } \\
\hline NCT02324257 [26] & Cibisatamab & I & Refractory & 68 & $6 \%$ & NA & NA \\
\hline NCT02650713 [26] & Cibisatamab + Atezolizumab & I & Refractory & 38 & $12 \%$ & NA & NA \\
\hline NCT04826003 & RO7122290 + Cibisatamab + Obinutuzumab & I & Refractory & Recruiting & NA & NA & NA \\
\hline NCT04468607 & BLYG8824A & I & Refractory & Recruiting & NA & NA & NA \\
\hline \multicolumn{8}{|l|}{ Vaccines } \\
\hline NCT01413295 [27] & Dendritic cell vaccine vs. BSC & II & $>2$ lines & 28 vs. 24 & $0 \%$ vs. $0 \%$ & 2.7 vs. 2.3 months & 6.2 vs. 4.7 months \\
\hline FXV [28] & & II & First line & $\begin{array}{l}46 \text { (HLA-A*2402- } \\
\text { unmatched) }\end{array}$ & $60.9 \%$ & 8.7 months & 24.0 months \\
\hline \multicolumn{8}{|l|}{ Intratumoral therapies } \\
\hline NCT00149396 [29] & $\begin{array}{l}\text { Hepatic artery infusion of NV1020 followed by } \\
\text { conventional chemotherapy }\end{array}$ & $\mathrm{I} / \mathrm{II}$ & Refractory & 22 & $4.5 \%$ & 6.4 months & 11.8 months \\
\hline NCT03256344 & Talimogene laherparepvec + Atezolizumab & $\mathrm{Ib}$ & Refractory & Active & NA & NA & NA \\
\hline
\end{tabular}




\subsection{Combination of Immune Checkpoint Inhibitors}

Given that the inhibition of the PD-1/PD-L1 axis alone has proven insufficient for pMMR/MSS mCRC, combined blockade with immunotherapy strategies has been explored to overcome immune resistance in this setting.

In the MSS refractory setting, combined immune checkpoint inhibition with the antiPDL-1 agent durvalumab plus the anti-CTLA-4 agent tremelimumab showed modest results in terms of response rate $(0.8 \%)$ and a trend in overall survival (OS) benefit with a 2.5-month improvement for the combination over best supportive care [11]. Exploratory analyses showed that patients presenting plasma TMB of 28 variants per megabase or more ( $21 \%$ of MSS tumors) had the greatest OS benefit (hazard ratio [HR]: $0.34, p=0.004$ ). Results from the phase I first-in-human clinical trial testing the anti-LAG-3 antiboy favezelimab and the anti-PD-1 pembrolizumab in previously treated patients with advanced MSS CRC were recently reported [12]. Of 89 patients receiving the combined blockade, four patients presented partial response and one patient achieved complete response. Median duration of response was 10.6 months (range 5.6-12.7) and toxicity was manageable.

\subsection{Immunotherapy in Combination with Chemotherapy}

\subsubsection{Immunotherapy in Combination with Chemotherapy and Anti-VEGF Agents}

Strategies based on the combination of chemotherapy with immunotherapy to overcome immune resistance of pMMR/MSS CRC have been widely explored, given that some chemotherapy agents may have an immune-stimulatory effect. There is evidence supporting that 5-fluorouracil (5-FU), the backbone of chemotherapy in CRC, induces apoptosis of myeloid-derived suppressor cells (MDSCs) and therefore favors tumor infiltration by CTLs $[30,31]$. Moreover, oxaliplatin induces tumor cell death, rendering tumor cells and cancer-specific antigens recognizable for the immune system and immunogenic cell death in cell lines derived from colorectal tumors by translocating the chaperone molecule calreticulin from the lumen of the endoplasmic reticulum to the cell surface [32-35]. An in vivo assay using an immune checkpoint blockade-resistant mouse xenograft model of colon cancer showed antitumor response when oxaliplatin was combined with immune checkpoint inhibitors [36].

Bevacizumab, an antiangiogenic agent widely used in the frontline treatment in combination with chemotherapy, inhibits the VEGF/VEGFR pathway upon binding to vascular endothelial growth factor A (VEGF-A). VEGF/VEGFR blockade leads to vasculature normalization, permitting increased tumor infiltration of $\mathrm{T}$ cells, and activation of effector immune cells through stimulation of the maturation of dendritic cells (DCs) and reduction of the expansion of Tregs and MDSCs [37-41].

These data provide the rationale to test the combination of chemotherapy with an antiangiogenic agent and immunotherapy in the clinical setting. However, the MODUL trial, which evaluated maintenance treatment with 5-FU and atezolizumab after first-line induction therapy with FOLFOX in patients with metastatic BRAF wild-type CRC did not show a significant difference in either PFS or OS [13]. More recently, results from the AtezoTRIBE study, in which frontline FOLFOXIRI and bevacizumab in combination with atezolizumab was compared with chemotherapy and bevacizumab alone, have been reported [14]. Of 218 patients included, 199 patients presented a diagnosis of advanced MSS CRC. In this subgroup, PFS was 12.9 months for the group treated with the combination and 11.4 months for the control group $(p=0.07)$. The combination of chemotherapy and immunotherapy in the frontline setting has also been evaluated in the phase II/III CA2099X8 trial evaluating FOLFOX combined with bevacizumab and nivolumab versus FOLFOX and bevacizumab (NCT03414983) and in the phase Ib/II COLUMBIA-1 trial comparing FOLFOX and bevacizumab in combination with durvalumab and oleclumab versus FOLFOX and bevacizumab (NCT04068610), for which outcomes are yet to be reported. Although the POCHI trial (NCT04262687) is currently exploring the combination of CAPOX and bevacizumab with pembrolizumab as first-line therapy in eligible patients 
with MSS mCRC who present a high immune infiltrate, no biomarker-based selection has been defined so far to optimize patient identification for this combined strategy.

In the chemo-refractory setting, the BACCI trial evaluated the addition of atezolizumab to capecitabine and bevacizumab [15]. Of 82 patients included in the experimental group and 46 patients in the control group, $86 \%$ and $87 \%$ presented MSS status. There were no statistical differences for ORR or PFS in the MSS sub-group between these treatments.

\subsubsection{Immunotherapy in Combination with Chemotherapy and Anti-EGFR Agents}

Standard therapy for the treatment of metastatic RAS/BRAF wild-type CRC includes the use of agents targeting the epidermal growth factor receptor (EGFR) in combination with chemotherapy.

Cetuximab, a chimeric IgG1 antibody, induces antibody-dependent cellular toxicity (ADCC) triggered by Fc $\gamma$ receptors on immune cells and promotes expression of MHC class II molecules on dendritic cells (DCs) [42-44], and is approved as part of management of CRC in several settings. The addition of avelumab to FOLFOX and cetuximab regardless of the microsatellite status in the frontline setting has been explored in the phase II AVETUX clinical trial. Although the combined treatment presented a response rate of $79.5 \%$, the actuarial PFS at 12 months was $40 \%$ and did not reach its primary endpoint (increase in progression-free rate at 12-month from $40 \%$ to 57\%) [16]. The combination of an intensified regimen using the triple-drug chemotherapy regimen FOLFOXIRI with either the antiEGFR cetuximab or panitumumab has been investigated in the MACBETH and VOLFI trials, respectively, showing a higher ORR. The addition of the anti-PD-L1 avelumab to FOLFOXIRI and cetuximab in the frontline setting for MSS RAS/BRAF wild-type $\mathrm{mCRC}$ is being evaluated in the phase II AVETRIC trial (NCT04513951). After induction therapy, maintenance treatment with 5-FU plus cetuximab and avelumab is scheduled until disease progression.

The use of immunotherapy for patients with $R A S / B R A F$ wild-type MSS CRC is being investigated beyond frontline therapy in a phase II clinical trial evaluating the combination of nivolumab and ipilimumab with panitumumab in patients who have received one or two prior lines of systemic treatment (NCT03442569). Based on the activity reported following rechallenge with EGFR-containing regimens for patients who previously experienced benefit with anti-EGFR agents [45], the phase II single-arm CAVE-Colon trial addresses the potential benefit of combining avelumab with cetuximab in the third-line setting, with no selection for microsatellite status [46]. Median OS of 11.6 months and a median PFS of 3.6 months were achieved. Plasma circulating tumor DNA (ctDNA) analysis before treatment may allow selection of patients who could benefit, as median OS and PFS were longer in patients with $R A S / B R A F$ WT ctDNA (17.3 vs. 10.4 months, $p=0.02$, and 4.1 vs. 3.0 months, $p=0.004$, respectively). Of 77 patients included, 71 (92\%) presented advanced MSS CRC. These preliminary results require further exploration in a randomized phase III setting in selected patients.

\subsubsection{Immunotherapy in Combination with Temozolomide}

Temozolomide (TMZ) is an oral alkylating agent whose mechanism of action lies in the methylation of DNA strands at the O6 position of guanine. This methylation damages DNA, provoking inhibition of replication and apoptosis. The O6-methylguanine methyltransferase (MGMT) enzyme coded by the MGMT gene reduces the therapeutic efficacy of TMZ [47]. Therefore, the effectiveness of TMZ in patients with advanced CRC is restricted to those tumors with MSS status, epigenetic silencing of MGMT mediated by the methylation of its promoter region, and no or low expression $[48,49]$. In a phase II clinical trial evaluating temozolomide in heavily pretreated patients whose tumors harbor MGMT promoter methylation, modest activity was observed, with an ORR of $10 \%$ and a disease control rate (DCR) of 32\% [50]. Acquired resistance to TMZ might be mediated by the emergence of mutations in the MMR machinery and the induction of hypermutation [51-53]. 
TMZ could therefore be useful as priming agent for immune-sensitization in pMMR/ MSS CRC. Results were recently reported for the phase II MAYA trial (NCT03832621), in which patients with chemo-refractory MSS CRC presenting MGMT silencing and benefiting from two cycles of TMZ, were treated with nivolumab and ipilimumab in combination with TMZ [17]. Actuarial PFS at 8 months was $36 \%$, ORR was $42 \%$ and median OS was 18.4 months, while paired biopsies showed acquired TMB-high after treatment initiation. The ARETHUSA trial (NCT03519412) in which patients with MSS CRC, who are MGMTnegative and promoter methylation-positive by immunohistochemistry and who present a TMB > 20 mutations per megabase after treatment with TMZ, will be treated with pembrolizumab, is currently recruiting.

\subsection{Immunotherapy in Combination with Antiangiogenic Agents}

Beyond the combination of chemotherapy and antiangiogenic agents with immunotherapy, combination of an antiangiogenic agent with immunotherapy but without chemotherapy has also been explored.

The potential immune-modulating effect of lenvatinib in combination with PD-1/L1 signal inhibitors has been studied in preclinical models. Combination of pembrolizumab and lenvatinib in syngeneic murine models led to activation of $\mathrm{CD} 8^{+} \mathrm{T}$ cells through reduction of TAMs, which are immune regulators in the TME, and to activation of the interferon pathway that resulted in a synergistic effect with greater reduction in tumor volume and higher response rate [54,55]. A non-randomized phase II trial conducted in patients with previously treated MSS CRC receiving pembrolizumab and lenvatinib showed promising antitumor activity with an ORR of $22 \%$, a median PFS of 2.3 months, and a manageable safety profile [18]. The randomized phase III trial comparing this immunotherapy-based combination versus standard of care (TAS102 or regorafenib) is currently recruiting (NCT04776148).

The combination of the multi-kinase inhibitor regorafenib with immunotherapy has also been explored, based on the ability of regorafenib to generate a more inflamed TME due to reduction of vessel permeability and TME infiltration by TAMs [56], the reduction of TAM proliferation and reprogramming into a subpopulation of cells with antitumor effects [57], and the blockade of IFN- $\gamma$-induced PD-L1 and IDO1 expression while maintaining MHC-I expression [58].

In light of these results, a phase Ib study evaluated the safety of nivolumab and regorafenib in 25 patients with pMMR CCR, resulting in a low ORR of $4.8 \%$, a median PFS of 4.3 months (95\% CI 2.1-15.6), and a median OS of 11 months [19]. The REGOMUNE trial, a single-arm, phase II study examined the efficacy and safety of regorafenib $160 \mathrm{mg}$ in combination with anti-PD-L1 blockade with avelumab in 48 patients with pMMR CRC. Although there were no responses, 23 patients presented stable disease $(54 \%)$, with a median PFS of 3.6 months (95\% CI 1.8-5.4), and a median OS of 10.8 months (95\% CI 5.9-NA). Increased tumor infiltration by $\mathrm{CD} 8^{+} \mathrm{T}$ cells at cycle 2 was associated with better outcomes [20].

\subsection{Immunotherapy in Combination with Radiotherapy}

Radiotherapy can enhance the immune response via multiple mechanisms. Locally, by damaging DNA, radiotherapy induces tumor-cell death-promoting antigen presentation and tumor-associated antigen-MHC complexes, T-cell recruitment and activation, and upregulation of inflammatory cytokines - enhancing the susceptibility of irradiated tumor cells to the immune system. Distantly, radiotherapy can induce an abscopal effect, which results in radiological responses outside the irradiated field mediated by an increase of immune-cell tumor infiltrates and direct presentation of tumor antigens [59].

There is preclinical evidence indicating that the pro-immune effects of locoregional radiotherapy can be synergistically augmented with immunostimulatory monoclonal antibodies to boost a regression in both irradiated tumor lesions and off-target lesions. This abscopal effect provides a basis for the rational design of combination therapy $[60,61]$. 
Double immune checkpoint inhibition and radiotherapy with the aim of obtaining an abscopal response was tested in a single arm phase II trial including evaluation of nonirradiated lesions. The combination of durvalumab and tremelimumab and radiotherapy resulted in an ORR of $8.3 \%$, a median PFS of 1.8 months, and a median OS of 11.4 months, not meeting the prespecified endpoint criteria. Nonetheless, combined radiotherapy with durvalumab and tremelimumab led to shrinkage of distant, nonirradiated tumors in MSS $\mathrm{mCRC}$, with manageable safety. Plus, a heightened $\mathrm{CD} 8^{+} \mathrm{T}$-cell activation, differentiation and proliferation was noted in patients with objective response [21]. In another phase II trial evaluating radiotherapy with ipilimumab and nivolumab, the combined treatment led to shrinkage of nonirradiated distant tumors with an ORR of $12.5 \%$ [22].

Other phase II clinical trials are currently assessing the activity of immune checkpoint inhibitors in combination with different strategies of locoregional radiation (standard radiotherapy stereotactic body radiotherapy and radiofrequency ablation) in the same setting (NCT02992912, NCT02437071, NCT03122509). Interestingly, the dose and fractionation employed may have an impact in the ability of radiotherapy to synergize with immunotherapy, since immune response genes have been shown to be expressed differentially in irradiated tumors according to the regimen used [62], while the ideal timing of administration with radiation may be dependent on the mechanism of action of the immunotherapy used [63].

\subsection{Immunotherapy in Combination with Target Therapy}

2.5.1. Immunotherapy in Combination with MAPK Signaling Inhibitors

Overexpression and activation of the RAS/BRAF/MEK/ERK pathway are commonly detected in CRC $[64,65]$. There is growing evidence that dysregulation of the MAPK pathway is associated with an immunosuppressive phenotype. Previous investigations have reported that MAPK signaling is essential for T-cell development, activation, proliferation, and survival and that MAPK signaling may control PD-L1 and CTLA-4 expression [66-71]. This provides the biological rationale to explore the synergic effect of immunotherapy agents and selective inhibitors of the RAS/BRAF/MEK/ERK pathway in pMMR/MSS mCRC.

\section{Immunotherapy in Combination with KRAS Inhibitors}

Analyses of the composition and functional distribution of the immune, fibroblastic, and angiogenic microenvironment of 1338 colorectal tumors from three independent cohorts unveiled that the CMS3 subtype, termed metabolic and that are enriched in tumors with KRAS mutations, displayed low immune and inflammatory signatures [72].

Despite extensive efforts at targeting KRAS, to date only KRAS G12C mutations have been demonstrated to be targetable, with a promising ORR of $32 \%$, a DCR of $88 \%$ and median PFS of 6.3 months were observed in pretreated patients with tumors harboring KRAS G12C mutations who received the KRAS G12C inhibitor sotorasib [73]. In the metastatic CRC sub-cohort, ORR, DCR, and PFS were 7\%, 74\%, and 4.0 months, respectively. Preclinical data using immune-competent mice showed that treatment with sotorasib induced a pro-inflammatory TME through increased interferon signaling, chemokine production, antigen processing, cytotoxic and natural killer cell activity, and stimulation of innate immune system [74]. Plus, combined treatment with immune-checkpoint inhibitors resulted in durable responses. Characterization of the molecular mechanisms underlying the synergistic effect of the combined blockade through immunophenotype analyses revealed an increased infiltration of $\mathrm{CD}^{+} \mathrm{T}$ cells, an increased number of total and proliferating $\mathrm{CD}^{+} \mathrm{T}$ cells, and the establishment of memory $\mathrm{T}$ cell response. Based on these in vivo experiments, combined inhibition of KRAS G12C and the PD-1/PD-L1 axis is being tested and clinical trials are currently recruiting (NCT03600883 and NCT04699188).

Efficacy of the combined treatment of KRAS and PD-1/PD-L1 inhibition with the SHP2 inhibitor TNO155 is also being tested in the phase Ib/II trial (NCT04699188), as SHP2 phosphatase is known to suppress T cell activation through CD28 dephosphorylation upon 
PD-1/PD-L1 ligation [75]. Therefore, triplet combination may exert increased antitumor activity as it may decrease intracellular PD-1 signaling and lead to a less suppressive TME.

Immunotherapy in Combination with BRAF Inhibitors

BRAF mutations in CRC occur in up to $15 \%$ of patients. The most frequent mutation is V600E, in which a valine in codon 600 is substituted for a glutamate at the amino acid level, and results in sustained RAS/RAF/MEK/ERK pathway signaling through constitutive activation of $B R A F$ kinase [76,77]. Patients with $\mathrm{mCRC}$ harboring $B R A F$ mutations present a poor prognosis and dismal median survival [78].

The single inhibition of BRAF in $\mathrm{mCRC}$ has proved ineffective due to feedback reactivation of EGFR and of the downstream immune-suppressive MAPK cascade [79,80]. However, the co-administration of the BRAF inhibitor with the EGFR inhibitor cetuximab, tested in the BEACON trial, resulted in significantly longer overall survival and a higher response rate than standard therapy, with a safety toxicity profile establishing a new standard of care for patients with previously treated BRAF-V600E-mutant CRC [81].

Paired tumor biopsies in patients with CRC harboring BRAF-V600E mutations and treated with triple-pronged therapy targeting BRAF, EGFR, and MEK showed that an increase in T-cell infiltration occurred after blockade of the MAPK pathway via BRAF inhibition [82]. Drawing from these findings, in vivo experiments using immune-competent murine models were performed. In vivo assays demonstrated the efficacy of the combined blockade of BRAF and the PD-1/PD-L1 axis over these strategies separately [82]. According to this rationale, the potential cooperativity between BRAF-targeting and the immune response is being further explored in two phase I trials testing the combination of the BRAF inhibitor dabrafenib, the MEK inhibitor trametinib and the anti-PD-1 antibody spartalizumab (NCT03668431), as well as the combination of dabrafenib, the ERK inhibitor LTT462, and spartalizumab (NCT04294160).

\section{Immunotherapy in Combination with MEK Inhibitors}

MEK inhibition in preclinical models led to upregulation of MHC I and a higher number of effector-phenotype antigen-specific $\mathrm{CD} 8^{+} \mathrm{T}$ cells within the tumor. In vivo studies combining MEK inhibition with blockade of the PD-1/PD-L1 axis resulted in synergistic and durable tumor regression in murine models of KRAS-mutated CRC [83,84].

Clinical exploration of this strategy in a phase $\mathrm{Ib}$ clinical trial evaluating the combination of atezolizumab plus the MEK inhibitor cobimetinib in 84 patients with chemorefractory CRC resulted in an ORR of $8 \%$ [23]. Interestingly, of seven patients presenting partial response, six had MSS tumors. Based on these results, the IMBLAZE370 phase III trial (COTEZO) randomized 363 patients with chemorefractory CRC to receive either atezolizumab plus cobimetinib, atezolizumab in monotherapy or regorafenib. However, the trial failed to meet its primary endpoint. Median OS was 8.9 months for the experimental arm, 8.5 months for the control arm with regorafenib, and 7.1 months for patients receiving atezolizumab. Moreover, there were no differences in terms of PFS and ORR across the treatment arms [24].

\subsubsection{Immunotherapy in Combination with Inhibition of the PI3K/AKT/mTOR Pathway}

PI3K pathway activation is often present in CRC, derived from the loss of PTEN and PIK3CA mutations and is associated with immune checkpoint upregulation [85]. Activating mutations in PIK3CA in in vivo assays confers resistance to anti-PD-1 agents, while coadministration with a PI3K inhibitor overcame resistance [86]. Meanwhile, PI3K $\gamma$ and PI3K $\delta$ isoforms might reprogram TAMs towards an immune-tolerant phenotype and PI3K inhibition would subsequently relieve Treg-mediated immunosuppression $[87,88]$. As a result of these findings, a phase I/II clinical trial exploring the potential efficacy of the combination of nivolumab with the PI3K inhibitor copanlisib is actively recruiting [25]. 


\subsection{Bispecific Antibodies}

Bispecific antibodies designed to recognize two different epitopes or antigens aim to address the host immune activity towards tumor cells by binding both tumor-enriched antigens (i.e., CEA, CEACAM, EpCAM, HER2, or CD276 antigen) and immune cells (mainly $T$ cells via the $C D 3$ receptor) and are being explored under this rationale in different types of solid tumors [89]. Some of these drugs are also being tested in combination with other agents, such as immune checkpoint inhibitors, to enhance antitumor activity [90].

Cibisatamab (RO6958688), a novel T-cell bispecific antibody targeting CEA on colorectal tumor cells and CD3 on T cells, is the bispecific antibody that is currently the furthest along the clinical development path for MSS mCRC. In preclinical models, cibisatamab displayed potent antitumor activity, leading to increased intratumoral $\mathrm{T}$ cell infiltration and activation and PD-1/PD-L1 upregulation [91]. Furthermore, blockade of the PD-1/PD-L1 axis in in vitro assays maximized tumoral T cell killing, directed by an anti-CEA bispecific antibody [92].

In two ongoing dose-escalation phase I studies, cibisatamab was given as monotherapy or in combination with atezolizumab in patients with solid tumors expressing CEA [26]. Consistent with its known mechanism of action, tumor inflammation was observed in CT scans on days of administration of the first dose of cibisatamab. Of 68 patients with $\mathrm{mCRC}$ treated with cibisatamab $(0.05$ to $600 \mathrm{mg})$ and of 38 patients with $\mathrm{mCRC}$ treated with cibisatamab (5-160 mg) in combination with atezolizumab, $10(28 \%)$ and $6(60 \%)$ respectively presented a metabolic partial response by PET scan four to six weeks after treatment initiation. Confirmed radiologic ORR for each group was $6 \%$ and $12 \%$, respectively. The most notable toxicities associated with cibisatamab are tumor inflammatory events and cytokine release syndrome due to immune-cell activation, occurring more often upon first exposure to cibisatamab.

Other bispecific T-cell engager antibodies are under development for MSS mCRC, including RO7122290 (a bispecific antibody-like fusion protein which connects a trimeric split 4-1BBL domain to a one-armed human IgG1 antibody directed against fibroblast activation protein) in combination with cibisatamab (NCT04826003) and BLYG8824A (a bispecific humanized IgG1 antibody binding the extracellular domain of LY6G6D and the CD3 subunit of the T cell-receptor) (NCT04468607).

\subsection{Cancer Vaccines}

Cancer vaccines are designed to trigger an intense response of the immune system to tumor-specific antigens. DC vaccines can be obtained by isolating DCs from the host, pulsing them ex vivo with tumor-associated antigens (TAAs) derived from autologous tumor lysate and then reinfusing them into the patient after activation. Upon infusion, the DCs present the TAAs on the cell surface, causing the activation of T cells and resulting in a cancer-specific immune response.

Despite the underlying rationale, disappointingly, little or no clinical efficacy has been observed so far with this strategy in MSS mCRC. Two phase II clinical trials, using autologous tumor lysate DC vs. best supportive care in patients with pretreated CRC [27] and a peptide vaccine based on the combination of five peptides derived from tumorassociated antigens (RNF43, TOMM34, KOC1, VEGFR1, and VEGFR2) with oxaliplatinbased chemotherapy in the frontline setting [28]; respectively, demonstrated the generation of a tumor-specific immune response but failed to demonstrate clinical benefit. Finally, the combination of vaccines with checkpoint inhibitors will probably overcome the immunosuppressive TME through enhancement of the immune response, due to intensified immunogenicity and an increased number of tumor-specific T cells. Preclinical assays showed that dual blockade of PD-1 and CTLA-4 combined with GM-CSF gene-transfected tumor cell vaccine (GVAX) in murine models of CRC resulted in tumor rejection in $100 \%$ of mice [93]. 


\subsection{Intratumoral Therapies}

Intratumoral administration of selected drugs in combination with other immune strategies may enhance antitumor response through attraction of immune cells to the tumor. Stimulator of interferon genes (STING) acts as an innate immune sensor for cytosolic DNA and its activation is crucial to trigger the type I interferon response and the antitumoral immune response by $\mathrm{CD} 8^{+} \mathrm{T}$ cells [94]. Intratumoral injection of synthetic STING agonists in murine CRC models resulted in impaired tumor growth mediated by an increase in intratumoral $\mathrm{CD}^{+} \mathrm{T}$ cell infiltration [95]. This preclinical therapeutic effect is now being explored in phase I clinical trials (NCT03843359).

Oncolytic viruses are genetically modified to ensure they are unable to damage the host's normal tissues, which may act as double-edged swords against tumors through direct cytolysis of cancer cells and the induction of antitumor immunity. A phase I/II clinical trial evaluated the safety and the antitumor activity of the genetically engineered oncolytic herpes simplex virus NV1020 administered via weekly hepatic artery infusion, followed by two or more cycles of conventional chemotherapy, in pretreated chemorefractory CRC patients with liver metastases [29]. Among the 22 patients treated, 50\% showed stable disease after NV1020 administration and 68\% presented DCR after treatment with chemotherapy (1 partial response and 14 stable disease); median time to progression was 6.4 months and median OS was 11.8 months. Talimogene laherparepvec-a modified herpes simplex virus approved for intratumoral treatment of unresectable recurrent cutaneous, subcutaneous, and nodal melanoma-is being tested in combination with atezolizumab for patients with CRC with liver involvement in a phase Ib trial (NCT03256344).

Other intratumoral strategies-including but not restricted to Toll-like receptor agonists, immune receptor agonists, immune cells, cytokines, and mRNA encoding cytokinesare also being explored.

\section{Conclusions}

Despite the clinical benefit of immunotherapy observed in patients with MSI mCRC, to date neither immunotherapy agents as monotherapy nor immunotherapy-based combinations have been approved for MSS MCRC, and a long road lies ahead for this entity.

Immunotherapy-based strategies that are currently under development include, among others, combination with chemotherapy, radiotherapy, or targeted therapies; bispecific antibodies; cancer vaccines; and intratumoral therapies. These strategies aim at turning an effective immune response against tumor cells. Unravelling the pathways mediating immune resistance in MSS colorectal tumors remains an ongoing challenge, along with optimizing rational immunotherapy-based combinations to render them amenable for these strategies, ameliorating patient selection, and improving prevention and management of immune-related adverse events such that the implementation of immunotherapy in this setting moves forward successfully.

Preclinical functional evidence obtained through the use of patient-derived modelsincluding patient-derived organoids and patient-derived xenografts-and the use of reverse translational studies may illuminate the path forward.

Funding: This research received no external funding.

Conflicts of Interest: I.B. declares to have received honoraria from Sanofi; and to have received travel and accommodations expenses from Amgen and Sanofi. J.R. declares to have received honoraria from Sanofi. F.S. declares to have received personal financial interest, honoraria for advisory role, travel grants and research grants from Hoffmann-La Roche Sanofi Aventis, Amgen, Merck Serono, Servier, Bristol Myers Squibb, and institutional financial honoraria due to investigator contribution in clinical trials from Hoffman La-Roche, Sanofi Aventis, Amgen, Merck Serono, MSD, Boehringer Ingelheim, AbbVie, Array Pharmaceuticals, Pierre-Fabre, Novartis, Bristol Myers Squibb, GlaxoSmithKline, Medimmune. J.T. declares personal financial interest in form of scientific consultancy role for Array Biopharma, AstraZeneca, Bayer, Boehringer Ingelheim, Chugai, F. Hoffmann-La Roche Ltd., Genentech Inc., HalioDX SAS, Ikena Oncology, IQVIA, Lilly, MSD, Menarini, Merck Serono, Mirati, Novartis, Peptomy, Pfizer, Pierre Fabre, Sanofi, Seattle Genetics, Servier, Taiho, Tessa Therapeutics, 
and TheraMyc. E.E. received honoraria for advisory role, travel grants, research grants from Hoffman La-Roche, Bristol Myers Squibb, Servier, Amgen, Merck Serono, Array Biopharma, Sanofi. E.É. declares institutional financial honoraria due to investigation contribution in clinical trials from Array Biopharma, MSD, Abbvie, Amgen, GlaxoSmithKline, AstraZeneca, Merck Sharp \& Dohme Corp., Bristol Myers Squibb, Novartis, Boehringer Ingelheim, Hoffman La-Roche. The authors have no other relevant affiliations or financial involvement with any organization or entity with a financial interest in or financial conflict with the subject matter or materials discussed in the manuscript apart from those disclosed.

\section{References}

1. Bray, F.; Ferlay, J.; Soerjomataram, I.; Siegel, R.L.; Torre, L.A.; Jemal, A. Global cancer statistics 2018: GLOBOCAN estimates of incidence and mortality worldwide for 36 cancers in 185 countries. CA Cancer J. Clin. 2018, 68, 394-424. [CrossRef] [PubMed]

2. The Cancer Genome Atlas Network. Comprehensive molecular characterization of human colon and rectal cancer. Nature 2012, 487, 330-337. [CrossRef]

3. Li, G.-M. Mechanisms and functions of DNA mismatch repair. Cell Res. 2008, 18, 85-98. [CrossRef] [PubMed]

4. Phillips, S.M.; Banerjea, A.; Feakins, R.; Li, S.R.; Bustin, S.A.; Dorudi, S. Tumour-infiltrating lymphocytes in colorectal cancer with microsatellite instability are activated and cytotoxic. Br. J. Surg. 2004, 91, 469-475. [CrossRef] [PubMed]

5. Guinney, J.; Dienstmann, R.; Wang, X.; De Reyniès, A.; Schlicker, A.; Soneson, C.; Marisa, L.; Roepman, P.; Nyamundanda, G.; Angelino, P.; et al. The consensus molecular subtypes of colorectal cancer. Nat. Med. 2015, 21, 1350-1356. [CrossRef] [PubMed]

6. André, T.; Shiu, K.-K.; Kim, T.W.; Jensen, B.V.; Jensen, L.H.; Punt, C.; Smith, D.; Garcia-Carbonero, R.; Benavides, M.; Gibbs, P.; et al. Pembrolizumab in Microsatellite-Instability-High Advanced Colorectal Cancer. N. Engl. J. Med. 2020, 383, 2207-2218. [CrossRef] [PubMed]

7. Le, D.T.; Uram, J.N.; Wang, H.; Bartlett, B.R.; Kemberling, H.; Eyring, A.D.; Skora, A.D.; Luber, B.S.; Azad, N.S.; Laheru, D.; et al. PD-1 Blockade in Tumors with Mismatch-Repair Deficiency. N. Engl. J. Med. 2015, 372, 2509-2520. [CrossRef] [PubMed]

8. Le, D.T.; Durham, J.N.; Smith, K.N.; Wang, H.; Bartlett, B.R.; Aulakh, L.K.; Lu, S.; Kemberling, H.; Wilt, C.; Luber, B.S.; et al. Mismatch repair deficiency predicts response of solid tumors to PD-1 blockade. Science 2017, 357, 409-413. [CrossRef] [PubMed]

9. Gong, J.; Wang, C.; Lee, P.P.; Chu, P.; Fakih, M. Response to PD-1 Blockade in Microsatellite Stable Metastatic Colorectal Cancer Harboring aPOLEMutation. J. Natl. Compr. Cancer Netw. 2017, 15, 142-147. [CrossRef] [PubMed]

10. Domingo, E.; Freeman-Mills, L.; Rayner, E.; Glaire, M.; Briggs, S.; Vermeulen, L.; Fessler, E.; Medema, J.P.; Boot, A.; Morreau, H.; et al. Somatic POLE proofreading domain mutation, immune response, and prognosis in colorectal cancer: A retrospective, pooled biomarker study. Lancet Gastroenterol. Hepatol. 2016, 1, 207-216. [CrossRef]

11. Chen, E.X.; Jonker, D.J.; Loree, J.; Kennecke, H.F.; Berry, S.R.; Couture, F.; Ahmad, C.E.; Goffin, J.R.; Kavan, P.; Harb, M.; et al. Effect of Combined Immune Checkpoint Inhibition vs. Best Supportive Care Alone in Patients with Advanced Colorectal Cancer. JAMA Oncol. 2020, 6, 831-838. [CrossRef]

12. Garralda, E.; Sukari, A.; Lakhani, N.J.; Patnaik, A.; Lou, Y.; Im, S.-A.; Golan, T.; Geva, R.; Wermke, M.; De Miguel, M.; et al. A phase 1 first-in-human study of the anti-LAG-3 antibody MK4280 (favezelimab) plus pembrolizumab in previously treated, advanced microsatellite stable colorectal cancer. J. Clin. Oncol. 2021, 39, 3584. [CrossRef]

13. Grothey, A.; Tabernero, J.; Arnold, D.; De Gramont, A.; Ducreux, M.; O’Dwyer, P.; Van Cutsem, E.; Bosanac, I.; Srock, S.; Mancao, C.; et al. Fluoropyrimidine (FP) + bevacizumab (BEV) + atezolizumab vs. FP/BEV in BRAFwt metastatic colorectal cancer (mCRC): Findings from Cohort 2 of MODUL-A multicentre, randomized trial of biomarker-driven maintenance treatment following first-line induction therapy. Ann. Oncol. 2018, 29, viii714-viii715. [CrossRef]

14. Cremolini, C.; Rossini, D.; Antoniotti, C.; Pietrantonio, F.; Lonardi, S.; Salvatore, L.; Marmorino, F.; Borelli, B.; Ambrosini, M.; Barsotti, G.; et al. LBA20 FOLFOXIRI plus bevacizumab (bev) plus atezolizumab (atezo) versus FOLFOXIRI plus bev as first-line treatment of unresectable metastatic colorectal cancer (mCRC) patients: Results of the phase II randomized AtezoTRIBE study by GONO. Ann. Oncol. 2021, 32, S1294-S1295. [CrossRef]

15. Mettu, N.; Twohy, E.; Ou, F.-S.; Halfdanarson, T.; Lenz, H.; Breakstone, R.; Boland, P.; Crysler, O.; Wu, C.; Grothey, A.; et al. BACCI: A phase II randomized, double-blind, multicenter, placebo-controlled study of capecitabine (C) bevacizumab (B) plus atezolizumab (A) or placebo (P) in refractory metastatic colorectal cancer (mCRC): An ACCRU network study. Ann. Oncol. 2019, 30, v203. [CrossRef]

16. Stein, A.; Binder, M.; Goekkurt, E.; Lorenzen, S.; Riera-Knorrenschild, J.; Depenbusch, R.; Ettrich, T.J.; Doerfel, S.; Al-Batran, S.-E.; Karthaus, M.; et al. Avelumab and cetuximab in combination with FOLFOX in patients with previously untreated metastatic colorectal cancer (MCRC): Final results of the phase II AVETUX trial (AIO-KRK-0216). J. Clin. Oncol. 2020, 38, 96. [CrossRef]

17. Pietrantonio, F.; Morano, F.; Lonardi, S.; Raimondi, A.; Salvatore, L.; Marmorino, F.; Murgioni, S.; Pella, N.; Antonuzzo, L.; Ritorto, G.; et al. 383O MAYA trial: Temozolomide (TMZ) priming followed by combination with low-dose ipilimumab and nivolumab in patients with microsatellite stable (MSS), MGMT silenced metastatic colorectal cancer (mCRC). Ann. Oncol. 2021, 32, S530-S531. [CrossRef]

18. Gomez-Roca, C.A.; Yanez, E.; Im, S.-A.; Castanon-Alvarez, E.; Senellart, H.; Doherty, M.; Garcia-Corbacho, J.; Lopez, J.S.; Basu, B.; Maurice-Dror, C.; et al. LEAP-005: A phase 2 multicohort study of lenvatinib plus pembrolizumab in patients with previously treated selected solid tumors-Results from the colorectal cancer cohort. J. Clin. Oncol. 2021, 39, 3564. [CrossRef] 
19. Kim, R.; Imanirad, I.; Carballido, E.; Strosberg, J.; Kim, Y.; Kim, D. O-20 Phase I/IB study of regorafenib and nivolumab in mismatch repair (MMR) proficient advanced refractory colorectal cancer. Ann. Oncol. 2020, 31, 239. [CrossRef]

20. Cousin, S.; Cantarel, C.; Guegan, J.-P.; Gomez-Roca, C.; Metges, J.-P.; Adenis, A.; Pernot, S.; Bellera, C.A.; Kind, M.; Auzanneau, C.; et al. Regorafenib-Avelumab Combination in Patients with Microsatellite Stable Colorectal Cancer (REGOMUNE): A Single-arm, Open-label, Phase II Trial. Clin. Cancer Res. 2021, 27, 2139-2147. [CrossRef]

21. Segal, N.H.; Cercek, A.; Ku, G.; Wu, A.J.; Rimner, A.; Khalil, D.N.; Reidy-Lagunes, D.; Cuaron, J.; Yang, T.J.; Weiser, M.R.; et al. Phase II Single-arm Study of Durvalumab and Tremelimumab with Concurrent Radiotherapy in Patients with Mismatch Repair-proficient Metastatic Colorectal Cancer. Clin. Cancer Res. 2021, 27, 2200-2208. [CrossRef]

22. Parikh, A.R.; Clark, J.W.; Wo, J.Y.-L.; Yeap, B.Y.; Allen, J.N.; Blaszkowsky, L.S.; Ryan, D.P.; Giantonio, B.J.; Weekes, C.D.; Zhu, A.X.; et al. A phase II study of ipilimumab and nivolumab with radiation in microsatellite stable (MSS) metastatic colorectal adenocarcinoma (mCRC). J. Clin. Oncol. 2019, 37, 3514. [CrossRef]

23. Hellmann, M.; Kim, T.-W.; Lee, C.; Goh, B.-C.; Miller, W.; Oh, D.-Y.; Jamal, R.; Chee, C.-E.; Chow, L.; Gainor, J.; et al. Phase Ib study of atezolizumab combined with cobimetinib in patients with solid tumors. Ann. Oncol. 2019, 30, 1134-1142. [CrossRef] [PubMed]

24. Eng, C.; Kim, T.W.; Bendell, J.; Argilés, G.; Tebbutt, N.C.; Di Bartolomeo, M.; Falcone, A.; Fakih, M.; Kozloff, M.; Segal, N.H.; et al. Atezolizumab with or without cobimetinib versus regorafenib in previously treated metastatic colorectal cancer (IMblaze370): A multicentre, open-label, phase 3, randomised, controlled trial. Lancet Oncol. 2019, 20, 849-861. [CrossRef]

25. Jakubowski, C.; Collins, N.B.; Sugar, E.A.; Berg, M.; Cao, H.; Giannakis, M.; Jaffee, E.M.; Azad, N.S. A phase I/II study of PI3Kinase inhibition with copanlisib combined with the anti-PD-1 antibody nivolumab in relapsed/refractory solid tumors with expansions in MSS colorectal cancer. J. Clin. Oncol. 2020, 38, TPS4114. [CrossRef]

26. Tabernero, J.; Melero, I.; Ros, W.; Argiles, G.; Marabelle, A.; Rodriguez-Ruiz, M.E.; Albanell, J.; Calvo, E.; Moreno, V.; Cleary, J.M.; et al. Phase Ia and Ib studies of the novel carcinoembryonic antigen (CEA) T-cell bispecific (CEA CD3 TCB) antibody as a single agent and in combination with atezolizumab: Preliminary efficacy and safety in patients with metastatic colorectal cancer (mCRC). J. Clin. Oncol. 2017, 35, 3002. [CrossRef]

27. Caballero-Baños, M.; Benitez-Ribas, D.; Tabera, J.; Varea, S.; Vilana, R.; Bianchi, L.; Ayuso, J.R.; Pagés, M.; Carrera, G.; Cuatrecasas, M.; et al. Phase II randomised trial of autologous tumour lysate dendritic cell plus best supportive care compared with best supportive care in pre-treated advanced colorectal cancer patients. Eur. J. Cancer 2016, 64, 167-174. [CrossRef] [PubMed]

28. Hazama, S.; Nakamura, Y.; Tanaka, H.; Hirakawa, K.; Tahara, K.; Shimizu, R.; Ozasa, H.; Etoh, R.; Sugiura, F.; Okuno, K.; et al. A phase II study of five peptides combination with oxaliplatin-based chemotherapy as a first-line therapy for advanced colorectal cancer (FXV study). J. Transl. Med. 2014, 12, 108. [CrossRef] [PubMed]

29. Geevarghese, S.K.; Geller, D.A.; De Haan, H.A.; Hörer, M.; Knoll, A.E.; Mescheder, A.; Nemunaitis, J.; Reid, T.R.; Sze, D.Y.; Tanabe, K.K.; et al. Phase I/II Study of Oncolytic Herpes Simplex Virus NV1020 in Patients with Extensively Pretreated Refractory Colorectal Cancer Metastatic to the Liver. Hum. Gene Ther. 2010, 21, 1119-1128. [CrossRef]

30. Vincent, J.; Mignot, G.; Chalmin, F.; Ladoire, S.; Bruchard, M.; Chevriaux, A.; Martin, F.; Apetoh, L.; Rébé, C.; Ghiringhelli, F. 5-Fluorouracil Selectively Kills Tumor-Associated Myeloid-Derived Suppressor Cells Resulting in Enhanced T Cell-Dependent Antitumor Immunity. Cancer Res. 2010, 70, 3052-3061. [CrossRef]

31. Kanterman, J.; Sade-Feldman, M.; Biton, M.; Ish-Shalom, E.; Lasry, A.; Goldshtein, A.; Hubert, A.; Baniyash, M. Adverse Immunoregulatory Effects of 5FU and CPT11 Chemotherapy on Myeloid-Derived Suppressor Cells and Colorectal Cancer Outcomes. Cancer Res. 2014, 74, 6022-6035. [CrossRef] [PubMed]

32. Gonzalez-Aparicio, M.; Alzuguren, P.; Mauleon, I.; Medina-Echeverz, J.; Hervas-Stubbs, S.; Mancheno, U.; Berraondo, P.; Crettaz, J.; Gonzalez-Aseguinolaza, G.; Prieto, J.; et al. Oxaliplatin in combination with liver-specific expression of interleukin 12 reduces the immunosuppressive microenvironment of tumours and eradicates metastatic colorectal cancer in mice. Gut 2011, 60, 341-349. [CrossRef] [PubMed]

33. Galaine, J.; Turco, C.; Vauchy, C.; Royer, B.; Mercier-Letondal, P.; Queiroz, L.; Loyon, R.; Mouget, V.; Boidot, R.; Laheurte, C.; et al. CD4 T cells target colorectal cancer antigens upregulated by oxaliplatin. Int. J. Cancer 2019, 145, 3112-3125. [CrossRef] [PubMed]

34. Dosset, M.; Rivera-Vargas, T.; Lagrange, A.; Boidot, R.; Vegran, F.; Roussey, A.; Chalmin, F.; Dondaine, L.; Paul, C.; Marie-Joseph, E.L.; et al. PD-1/PD-L1 pathway: An adaptive immune resistance mechanism to immunogenic chemotherapy in colorectal cancer. OncoImmunology 2018, 7, e1433981. [CrossRef] [PubMed]

35. di Blasio, S.; Wortel, I.M.N.; Van Bladel, D.A.G.; de Vries, L.E.; Duiveman-de Boer, T.; Worah, K.; de Haas, N.; Buschow, S.I.; De Vries, I.J.M.; Figdor, C.G.; et al. Human CD1c(+) DCs are critical cellular mediators of immune responses induced by immunogenic cell death. OncoImmunology 2016, 5, e1192739. [CrossRef] [PubMed]

36. Wang, W.; Wu, L.; Zhang, J.; Wu, H.; Han, E.; Guo, Q. Chemoimmunotherapy by combining oxaliplatin with immune checkpoint blockades reduced tumor burden in colorectal cancer animal model. Biochem. Biophys. Res. Commun. 2017, 487, 1-7. [CrossRef]

37. Limagne, E.; Euvrard, R.; Thibaudin, M.; Rébé, C.; Derangère, V.; Chevriaux, A.; Boidot, R.; Vegran, F.; Bonnefoy, N.; Vincent, J.; et al. Accumulation of MDSC and Th17 Cells in Patients with Metastatic Colorectal Cancer Predicts the Efficacy of a FOLFOX-Bevacizumab Drug Treatment Regimen. Cancer Res. 2016, 76, 5241-5252. [CrossRef]

38. Terme, M.; Pernot, S.; Marcheteau, E.; Sandoval, F.; Benhamouda, N.; Colussi, O.; Dubreuil, O.; Carpentier, A.F.; Tartour, E.; Taieb, J. VEGFA-VEGFR Pathway Blockade Inhibits Tumor-Induced Regulatory T-cell Proliferation in Colorectal Cancer. Cancer Res. 2013, 73, 539-549. [CrossRef] 
39. Gabrilovich, D.I.; Chen, H.L.; Girgis, K.R.; Cunningham, H.T.; Meny, G.M.; Nadaf, S.; Kavanaugh, D.; Carbone, D.P. Production of vascular endothelial growth factor by human tumors inhibits the functional maturation of dendritic cells. Nat. Med. 1996, 2, 1096-1103. [CrossRef]

40. Gavalas, N.G.; Tsiatas, M.; Tsitsilonis, O.; Politi, E.; Ioannou, K.; Ziogas, A.C.; Rodolakis, A.; Vlahos, G.; Thomakos, N.; Haidopoulos, D.; et al. VEGF directly suppresses activation of T cells from ascites secondary to ovarian cancer via VEGF receptor type. Br. J. Cancer 2012, 107, 1869-1875. [CrossRef]

41. Osada, T.; Chong, G.; Tansik, R.; Hong, T.; Spector, N.; Kumar, R.; Hurwitz, H.I.; Dev, I.; Nixon, A.B.; Lyerly, H.K.; et al. The effect of anti-VEGF therapy on immature myeloid cell and dendritic cells in cancer patients. Cancer Immunol. Immunother. 2008, 57, 1115-1124. [CrossRef] [PubMed]

42. Trotta, A.M.; Ottaiano, A.; Romano, C.; Nasti, G.; Nappi, A.; De Divitiis, C.; Napolitano, M.; Zanotta, S.; Casaretti, R.; D'Alterio, C.; et al. Prospective Evaluation of Cetuximab-Mediated Antibody-Dependent Cell Cytotoxicity in Metastatic Colorectal Cancer Patients Predicts Treatment Efficacy. Cancer Immunol. Res. 2016, 4, 366-374. [CrossRef] [PubMed]

43. Kimura, H.; Sakai, K.; Arao, T.; Shimoyama, T.; Tamura, T.; Nishio, K. Antibody-dependent cellular cytotoxicity of cetuximab against tumor cells with wild-type or mutant epidermal growth factor receptor. Cancer Sci. 2007, 98, 1275-1280. [CrossRef] [PubMed]

44. Wang, L.; Wei, Y.; Fang, W.; Lu, C.; Chen, J.; Cui, G.; Diao, H. Cetuximab Enhanced the Cytotoxic Activity of Immune Cells during Treatment of Colorectal Cancer. Cell. Physiol. Biochem. 2017, 44, 1038-1050. [CrossRef]

45. Cremolini, C.; Rossini, D.; Dell'Aquila, E.; Lonardi, S.; Conca, E.; Del Re, M.; Busico, A.; Pietrantonio, F.; Danesi, R.; Aprile, G.; et al. Rechallenge for Patients With RAS and BRAF Wild-Type Metastatic Colorectal Cancer With Acquired Resistance to First-line Cetuximab and Irinotecan. JAMA Oncol. 2019, 5, 343-350. [CrossRef] [PubMed]

46. Martinelli, E.; Martini, G.; Famiglietti, V.; Troiani, T.; Napolitano, S.; Pietrantonio, F.; Ciardiello, D.; Terminiello, M.; Borrelli, C.; Vitiello, P.P.; et al. Cetuximab Rechallenge Plus Avelumab in Pretreated Patients With RAS Wild-type Metastatic Colorectal Cancer: The Phase 2 Single-Arm Clinical CAVE Trial. JAMA Oncol. 2021, 7, 1529. [CrossRef]

47. Hegi, M.E.; Diserens, A.-C.; Gorlia, T.; Hamou, M.-F.; De Tribolet, N.; Weller, M.; Kros, J.M.; Hainfellner, J.A.; Mason, W.; Mariani, L.; et al. MGMTGene Silencing and Benefit from Temozolomide in Glioblastoma. N. Engl. J. Med. 2005, 352, 997-1003. [CrossRef] [PubMed]

48. Schwartz, S.; Szeto, C.; Tian, Y.; Cecchi, F.; Corallo, S.; Calegari, M.A.; Di Bartolomeo, M.; Morano, F.; Raimondi, A.; Fucà, G.; et al. Refining the selection of patients with metastatic colorectal cancer for treatment with temozolomide using proteomic analysis of O6-methylguanine-DNA-methyltransferase. Eur. J. Cancer 2019, 107, 164-174. [CrossRef]

49. Sartore-Bianchi, A.; Pietrantonio, F.; Amatu, A.; Milione, M.; Cassingena, A.; Ghezzi, S.; Caporale, M.; Berenato, R.; Falcomatà, C.; Pellegrinelli, A.; et al. Digital PCR assessment of MGMT promoter methylation coupled with reduced protein expression optimises prediction of response to alkylating agents in metastatic colorectal cancer patients. Eur. J. Cancer 2017, 71, 43-50. [CrossRef]

50. Calegari, M.A.; Inno, A.; Monterisi, S.; Orlandi, A.; Santini, D.; Basso, M.; Cassano, A.; Martini, M.; Cenci, T.; De Pascalis, I.; et al. A phase 2 study of temozolomide in pretreated metastatic colorectal cancer with MGMT promoter methylation. Br. J. Cancer 2017, 116, 1279-1286. [CrossRef]

51. Yip, S.; Miao, J.; Cahill, D.; Iafrate, A.J.; Aldape, K.; Nutt, C.L.; Louis, D.N. MSH6 Mutations Arise in Glioblastomas during Temozolomide Therapy and Mediate Temozolomide Resistance. Clin. Cancer Res. 2009, 15, 4622-4629. [CrossRef]

52. Hunter, C.; Smith, R.; Cahill, D.P.; Stephens, P.; Stevens, C.; Teague, J.; Greenman, C.; Edkins, S.; Bignell, G.; Davies, H.; et al. A Hypermutation Phenotype and Somatic MSH6 Mutations in Recurrent Human Malignant Gliomas after Alkylator Chemotherapy. Cancer Res. 2006, 66, 3987-3991. [CrossRef] [PubMed]

53. Germano, G.; Lamba, S.E.; Rospo, G.; Barault, L.; Magrì, A.; Maione, F.; Russo, M.; Crisafulli, G.; Bartolini, A.; Lerda, G.; et al. Inactivation of DNA repair triggers neoantigen generation and impairs tumour growth. Nature 2017, 552, 116-120. [CrossRef] [PubMed]

54. Kato, Y.; Tabata, K.; Kimura, T.; Yachie-Kinoshita, A.; Ozawa, Y.; Yamada, K.; Ito, J.; Tachino, S.; Hori, Y.; Matsuki, M.; et al. Lenvatinib plus anti-PD-1 antibody combination treatment activates CD8+ $\mathrm{T}$ cells through reduction of tumor-associated macrophage and activation of the interferon pathway. PLoS ONE 2019, 14, e0212513. [CrossRef] [PubMed]

55. Kimura, T.; Kato, Y.; Ozawa, Y.; Kodama, K.; Ito, J.; Ichikawa, K.; Yamada, K.; Hori, Y.; Tabata, K.; Takase, K.; et al. Immunomodulatory activity of lenvatinib contributes to antitumor activity in the Hepa1-6 hepatocellular carcinoma model. Cancer Sci. 2018, 109, 3993-4002. [CrossRef]

56. Abou-Elkacem, L.; Arns, S.; Brix, G.; Gremse, F.; Zopf, D.; Kiessling, F.; Lederle, W. Regorafenib Inhibits Growth, Angiogenesis, and Metastasis in a Highly Aggressive, Orthotopic Colon Cancer Model. Mol. Cancer Ther. 2013, 12, 1322-1331. [CrossRef] [PubMed]

57. Chen, C.-W.; Ou, D.-L.; Hsu, C.-L.; Lin, L.; Cheng, A.-L.; Hsu, C. Regorafenib may enhance efficacy of anti-program cell death-1 therapy in hepatocellular carcinoma through modulation of macrophage polarization. J. Hepatol. 2019, 70, e605-e606. [CrossRef]

58. Wu, R.-Y.; Kong, P.-F.; Xia, L.-P.; Huang, Y.; Li, Z.-L.; Tang, Y.-Y.; Chen, Y.-H.; Li, X.; Senthilkumar, R.; Zhang, H.-L.; et al. Regorafenib Promotes Antitumor Immunity via Inhibiting PD-L1 and IDO1 Expression in Melanoma. Clin. Cancer Res. 2019, 25, 4530-4541. [CrossRef] [PubMed] 
59. Abuodeh, Y.; Venkat, P.; Kim, S. Systematic review of case reports on the abscopal effect. Curr. Probl. Cancer 2016, $40,25-37$. [CrossRef]

60. Rodriguez-Ruiz, M.E.; Rodriguez, I.; Barbes, B.; Mayorga, L.; Sanchez-Paulete, A.R.; Ponz-Sarvise, M.; Pérez-Gracia, J.L.; Melero, I. Brachytherapy attains abscopal effects when combined with immunostimulatory monoclonal antibodies. Brachytherapy 2017, 16, 1246-1251. [CrossRef]

61. Deng, L.; Liang, H.; Burnette, B.; Beckett, M.; Darga, T.; Weichselbaum, R.R.; Fu, Y.-X. Irradiation and anti-PD-L1 treatment synergistically promote antitumor immunity in mice. J. Clin. Investig. 2014, 124, 687-695. [CrossRef] [PubMed]

62. Vanpouille-Box, C.; Aryankalayil, M.; Pilones, K.; Formenti, S.; Coleman, C.N.; Demaria, S. Fractionated but not single dose radiation releases key signals of in situ tumor vaccination. J. Immunother. Cancer 2014, 2, P164. [CrossRef]

63. Young, K.H.; Baird, J.R.; Savage, T.; Cottam, B.; Friedman, D.; Bambina, S.; Messenheimer, D.J.; Fox, B.; Newell, P.; Bahjat, K.S.; et al. Optimizing Timing of Immunotherapy Improves Control of Tumors by Hypofractionated Radiation Therapy. PLoS ONE 2016, 11, e0157164. [CrossRef] [PubMed]

64. Forrester, K.; Almoguera, C.; Han, K.; Grizzle, W.E.; Perucho, M. Detection of high incidence of K-ras oncogenes during human colon tumorigenesis. Nat. Cell Biol. 1987, 327, 298-303. [CrossRef] [PubMed]

65. Fang, J.Y.; Richardson, B.C. The MAPK signalling pathways and colorectal cancer. Lancet Oncol. 2005, 6, 322-327. [CrossRef]

66. Kumar, S.; Principe, D.R.; Singh, S.K.; Viswakarma, N.; Sondarva, G.; Rana, B.; Rana, A. Mitogen-Activated Protein Kinase Inhibitors and T-Cell-Dependent Immunotherapy in Cancer. Pharmaceuticals 2020, 13, 9. [CrossRef]

67. D'Souza, W.N.; Chang, C.-F.; Fischer, A.M.; Li, M.; Hedrick, S.M. The Erk2 MAPK Regulates CD8 T Cell Proliferation and Survival. J. Immunol. 2008, 181, 7617-7629. [CrossRef]

68. Vella, L.; Pasam, A.; Dimopoulos, N.; Andrews, M.; Knights, A.; Puaux, A.-L.; Louahed, J.; Chen, W.; Woods, K.; Cebon, J. MEK Inhibition, Alone or in Combination with BRAF Inhibition, Affects Multiple Functions of Isolated Normal Human Lymphocytes and Dendritic Cells. Cancer Immunol. Res. 2014, 2, 351-360. [CrossRef] [PubMed]

69. Liao, W.; Overman, M.J.; Boutin, A.T.; Shang, X.; Zhao, D.; Dey, P.; Li, J.; Wang, G.; Lan, Z.; Li, J.; et al. KRAS-IRF2 Axis Drives Immune Suppression and Immune Therapy Resistance in Colorectal Cancer. Cancer Cell 2019, 35, 559-572. [CrossRef] [PubMed]

70. Lal, N.; White, B.S.; Goussous, G.; Pickles, O.; Mason, M.; Beggs, A.; Taniere, P.; Willcox, B.E.; Guinney, J.; Middleton, G.W. KRAS Mutation and Consensus Molecular Subtypes 2 and 3 Are Independently Associated with Reduced Immune Infiltration and Reactivity in Colorectal Cancer. Clin. Cancer Res. 2018, 24, 224-233. [CrossRef]

71. Blaj, C.; Schmidt, E.M.; Lamprecht, S.; Hermeking, H.; Jung, A.; Kirchner, T.; Horst, D. Oncogenic Effects of High MAPK Activity in Colorectal Cancer Mark Progenitor Cells and Persist Irrespective of RAS Mutations. Cancer Res. 2017, 77, 1763-1774. [CrossRef]

72. Becht, E.; De Reyniès, A.; Giraldo, N.; Pilati, C.; Buttard, B.; Lacroix, L.; Selves, J.; Sautes-Fridman, C.; Laurent-Puig, P.; Fridman, W.H. Immune and Stromal Classification of Colorectal Cancer Is Associated with Molecular Subtypes and Relevant for Precision Immunotherapy. Clin. Cancer Res. 2016, 22, 4057-4066. [CrossRef] [PubMed]

73. Hong, D.S.; Fakih, M.G.; Strickler, J.H.; Desai, J.; Durm, G.A.; Shapiro, G.I.; Falchook, G.S.; Price, T.J.; Sacher, A.; Denlinger, C.S.; et al. KRASG12C Inhibition with Sotorasib in Advanced Solid Tumors. N. Engl. J. Med. 2020, 383, 1207-1217. [CrossRef] [PubMed]

74. Canon, J.; Rex, K.; Saiki, A.Y.; Mohr, C.; Cooke, K.; Bagal, D.; Gaida, K.; Holt, T.; Knutson, C.G.; Koppada, N.; et al. The clinical KRAS(G12C) inhibitor AMG 510 drives anti-tumour immunity. Nature 2019, 575, 217-223. [CrossRef]

75. Hui, E.; Cheung, J.; Zhu, J.; Su, X.; Taylor, M.J.; Wallweber, H.A.; Sasmal, D.K.; Huang, J.; Kim, J.M.; Mellman, I.; et al. T cell costimulatory receptor CD28 is a primary target for PD-1-mediated inhibition. Science 2017, 355, 1428-1433. [CrossRef]

76. De Roock, W.; Claes, B.; Bernasconi, D.; De Schutter, J.; Biesmans, B.; Fountzilas, G.; Kalogeras, K.T.; Kotoula, V.; Papamichael, D.; Laurent-Puig, P.; et al. Effects of KRAS, BRAF, NRAS, and PIK3CA mutations on the efficacy of cetuximab plus chemotherapy in chemotherapy-refractory metastatic colorectal cancer: A retrospective consortium analysis. Lancet Oncol. 2010, 11, 753-762. [CrossRef]

77. Sorbye, H.; Dragomir, A.; Sundström, M.; Pfeiffer, P.; Thunberg, U.; Bergfors, M.; Aasebø, K.; Eide, G.E.; Ponten, F.; Qvortrup, C.; et al. High BRAF Mutation Frequency and Marked Survival Differences in Subgroups According to KRAS/BRAF Mutation Status and Tumor Tissue Availability in a Prospective Population-Based Metastatic Colorectal Cancer Cohort. PLoS ONE 2015, 10, e0131046. [CrossRef]

78. Tran, B.; Kopetz, S.; Tie, J.; Gibbs, P.; Jiang, Z.-Q.; Lieu, C.H.; Agarwal, A.; Maru, D.M.; Sieber, O.; Desai, J. Impact of BRAF mutation and microsatellite instability on the pattern of metastatic spread and prognosis in metastatic colorectal cancer. Cancer 2011, 117, 4623-4632. [CrossRef]

79. Corcoran, R.B.; Ebi, H.; Turke, A.B.; Coffee, E.M.; Nishino, M.; Cogdill, A.; Brown, R.D.; Della Pelle, P.; Dias-Santagata, D.; Hung, K.E.; et al. EGFR-Mediated Reactivation of MAPK Signaling Contributes to Insensitivity of BRAF-Mutant Colorectal Cancers to RAF Inhibition with Vemurafenib. Cancer Discov. 2012, 2, 227-235. [CrossRef]

80. Prahallad, A.; Sun, C.; Huang, S.; Di Nicolantonio, F.; Salazar, R.; Zecchin, D.; Beijersbergen, R.L.; Bardelli, A.; Bernards, R. Unresponsiveness of colon cancer to BRAF(V600E) inhibition through feedback activation of EGFR. Nature 2012, 483, 100-103. [CrossRef]

81. Kopetz, S.; Grothey, A.; Yaeger, R.; Van Cutsem, E.; Desai, J.; Yoshino, T.; Wasan, H.; Ciardiello, F.; Loupakis, F.; Hong, Y.S.; et al. Encorafenib, Binimetinib, and Cetuximab in BRAF V600E-Mutated Colorectal Cancer. N. Engl. J. Med. 2019, 381, 1632-1643. [CrossRef] [PubMed] 
82. Corcoran, R.; Giannakis, M.; Allen, J.; Chen, J.; Pelka, K.; Chao, S.; Meyerhardt, J.; Enzinger, A.; Enzinger, P.; McCleary, N.; et al. SO-26 Clinical efficacy of combined BRAF, MEK, and PD-1 inhibition in BRAFV600E colorectal cancer patients. Ann. Oncol. 2020, 31, S226-S227. [CrossRef]

83. Ebert, P.J.; Cheung, J.; Yang, Y.; McNamara, E.; Hong, R.; Moskalenko, M.; Gould, S.E.; Maecker, H.; Irving, B.A.; Kim, J.M.; et al. MAP Kinase Inhibition Promotes T Cell and Anti-tumor Activity in Combination with PD-L1 Checkpoint Blockade. Immunity 2016, 44, 609-621. [CrossRef] [PubMed]

84. Liu, L.; Mayes, P.A.; Eastman, S.; Shi, H.; Yadavilli, S.; Zhang, T.; Yang, J.; Seestaller-Wehr, L.; Zhang, S.-Y.; Hopson, C.; et al. The BRAF and MEK Inhibitors Dabrafenib and Trametinib: Effects on Immune Function and in Combination with Immunomodulatory Antibodies Targeting PD-1, PD-L1, and CTLA-4. Clin. Cancer Res. 2015, 21, 1639-1651. [CrossRef]

85. Nusrat, M.; Roszik, J.; Katkhuda, R.; Menter, D.; Raghav, K.P.S.; Morris, V.K.; Sharma, P.; Allison, J.P.; Blando, J.M.; Maru, D.M.; et al. Association of phosphatidylinositol 3-kinase (PI3K) pathway activation with increased immune checkpoint expression in colorectal cancer (CRC) patients. J. Clin. Oncol. 2018, 36, 653. [CrossRef]

86. Collins, N.B.; Abosy, R.A.; Miller, B.; Bi, K.; Manguso, R.; Yates, K.; Haining, W.N. PI3K activated tumors evade tumor immunity by promoting an inhibitory myeloid microenvironment. J. Immunol. 2019, 202, 58.17.

87. Ahmad, S.; Abu Eid, R.; Shrimali, R.; Webb, M.; Verma, V.; Doroodchi, A.; Berrong, Z.; Samara, R.; Rodriguez, P.C.; Mkrtichyan, M.; et al. Differential PI3K $\delta$ Signaling in CD4+ T-cell Subsets Enables Selective Targeting of T Regulatory Cells to Enhance Cancer Immunotherapy. Cancer Res. 2017, 77, 1892-1904. [CrossRef]

88. Carnevalli, L.S.; Sinclair, C.; Taylor, M.A.; Morentin-Gutierrez, P.; Langdon, S.; Coenen-Stass, A.M.L.; Mooney, L.; Hughes, A.; Jarvis, L.; Staniszewska, A.; et al. PI3K $\alpha / \delta$ inhibition promotes anti-tumor immunity through direct enhancement of effector CD8+ T-cell activity. J. Immunother. Cancer 2018, 6, 158. [CrossRef]

89. Labrijn, A.F.; Janmaat, M.L.; Reichert, J.M.; Parren, P.W.H.I. Bispecific antibodies: A mechanistic review of the pipeline. Nat. Rev. Drug Discov. 2019, 18, 585-608. [CrossRef]

90. Chang, C.-H.; Wang, Y.; Li, R.; Rossi, D.L.; Liu, D.; Rossi, E.A.; Cardillo, T.M.; Goldenberg, D.M. Combination Therapy with Bispecific Antibodies and PD-1 Blockade Enhances the Antitumor Potency of T Cells. Cancer Res. 2017, 77, 5384-5394. [CrossRef]

91. Bacac, M.; Fauti, T.; Sam, J.; Colombetti, S.; Weinzierl, T.; Ouaret, D.; Bodmer, W.F.; Lehmann, S.; Hofer, T.; Hosse, R.J.; et al. A Novel Carcinoembryonic Antigen T-Cell Bispecific Antibody (CEA TCB) for the Treatment of Solid Tumors. Clin. Cancer Res. 2016, 22, 3286-3297. [CrossRef] [PubMed]

92. Osada, T.; Patel, S.P.; Hammond, S.A.; Osada, K.; Morse, M.A.; Lyerly, H. CEA/CD3-bispecific T cell-engaging (BiTE) antibodymediated T lymphocyte cytotoxicity maximized by inhibition of both PD1 and PD-L1. Cancer Immunol. Immunother. 2015, 64, 677-688. [CrossRef] [PubMed]

93. Duraiswamy, J.; Kaluza, K.M.; Freeman, G.J.; Coukos, G. Dual Blockade of PD-1 and CTLA-4 Combined with Tumor Vaccine Effectively Restores T-Cell Rejection Function in Tumors. Cancer Res. 2013, 73, 3591-3603. [CrossRef]

94. Ishikawa, H.; Ma, Z.; Barber, G.N. STING regulates intracellular DNA-mediated, type I interferon-dependent innate immunity. Nature 2009, 461, 788-792. [CrossRef] [PubMed]

95. Chon, H.J.; Kim, H.; Noh, J.H.; Yang, H.; Lee, W.S.; Kong, S.J.; Lee, S.J.; Lee, Y.S.; Kim, W.R.; Kim, J.H.; et al. STING signaling is a potential immunotherapeutic target in colorectal cancer. J. Cancer 2019, 10, 4932-4938. [CrossRef] 